\title{
Non-invasive assessment of haemodynamic parameters in patients after Fontan procedure
}

\author{
Piotr Gutknecht ${ }^{1, \mathrm{~B}-\mathrm{F} \oplus}$, Joanna Kwiatkowska ${ }^{2, \mathrm{~B}-\mathrm{F} \oplus}$, Anna Wałdoch $^{2, \mathrm{~B}-\mathrm{C} \oplus}$, Konrad Siebert $^{1, \mathrm{~B}-\mathrm{D} \oplus}$, \\ Janusz Siebert ${ }^{1, A, C-F} \oplus$ \\ 1 University Centre for Cardiology, Department of Family Medicine, Medical University, Gdansk, Poland \\ 2 Department of Paediatric Cardiology and Congenital Heart Diseases, Medical University, Gdansk, Poland \\ A - Research concept and design, B - Collection and/or assembly of data, C - Data analysis and interpretation, \\ $D$ - Writing the article, E - Critical revision of the article, F- Final approval of article
}

Gutknecht P, Kwiatkowska J, Wałdoch A, Siebert K, Siebert J. Non-invasive assessment of haemodynamic parameters in patients after Fontan procedure. Ann Agric Environ Med. 2020; 27(3): 384-387. doi: 10.26444/aaem/109973

\begin{abstract}
I Abstract
Introduction and objective. Single ventricle anomaly is one of the complex congenital heart defects. A dependable non-invasive method of evaluation of Fontan circulation haemodynamics for early diagnosing unstable patients is hardly available in routine clinical practice. The aim of the study is non-invasive evaluation of the haemodynamic parameters in patients after Fontan operation.

Materials and method. The study involved 11 participants (age $24.4 \pm 4.3$ years) with functionally univentricular hearts after Fontan operation. Evaluation of haemodynamic parameters was performed in supine and sitting positions using the impedance cardiography method.

Results. In comparative analysis, heart rate (70.1 vs.78.3 1/min; $p=0.001)$, diastolic blood pressure (73.9 vs. $76.7 \mathrm{~mm} \mathrm{Hg}$; $p=0.026)$, mean arterial blood pressure $(84.5$ vs. $88.0 \mathrm{~mm} \mathrm{Hg} ; \mathrm{p}=0.013)$, systemic vascular resistance (1284.8 vs. 1334.9 dyn* $\left.{ }^{*}{ }^{*} \mathrm{~cm}^{-5} ; p=0.024\right)$, systemic vascular resistance index ( 2178.7 vs. $2272.8 \mathrm{dyn}{ }^{*} \mathrm{~s}^{*} \mathrm{~cm}^{-5 *} \mathrm{~m}^{2} ; \mathrm{p}=0.018$ ), pre-ejection period (124.2 vs. $136.2 \mathrm{~ms} ; p=0.009)$, systolic time ratio ( 0.43 vs. $0.53 ; p=0.0001)$, and $Z$ o ( 26.2 vs. $28.7 \Omega ; p<0.00001)$, were significantly higher in the sitting position. Stroke volume ( 75.4 vs. $68.5 \mathrm{ml} ; \mathrm{p}=0.013)$, stroke index ( $\left.42.7 \mathrm{vs} .39 .0 \mathrm{ml}^{*} \mathrm{~m}^{-2} ; \mathrm{p}=0.014\right)$, thoracic fluid content (38.5 vs. $\left.35.41^{*} \mathrm{k} \Omega^{-1} ; \mathrm{p}=<0.00001\right)$, thoracic fluid content index (22.8 vs. $\left.21.01^{*} \mathrm{k} \Omega^{-1 *} \mathrm{~m}^{-2} ; \mathrm{p}=<0.00001\right)$, and leftventricular ejection time 291.1 vs. $260.1 \mathrm{~ms} ; \mathrm{p}=<0.00001$, were significantly higher in the supine position.

Conclusions. In patients after Fontan procedure, impedance cardiography can be a useful tool the assessment of shortterm haemodynamic changes provoked by postural changes. Its clinical value in patients with congenital heart defects should be further investigated.
\end{abstract}

\section{Key words}

congenital heart disease, Fontan circulation, impedance cardiography, haemodynamics

\section{INTRODUCTION}

A significant number of all patients undergoing surgery for congenital cardiac disease are those with a functionally univentricular heart [1]. In the European Association for Cardio-Thoracic Surgery, Congenital Heart Surgery Databases and the Society of Thoracic Surgeons Fontan constituted 3.2\% of all cardiac operations during 4 years observation [1].

The blood circulatory system in healthy subjects consists of the systemic and pulmonary circulation [2]. In patients after Fontan operations, there is a need for compensation for the lack of a subpulmonary ventricle [3]. The Fontan operation was first performed in 1968 and is a functional palliation for patients with univentricular anatomy. It is also connected with higher mortality and morbidity in adults [4, 5]. Most patients after a Fontan-type procedure have a good quality of life. On the other hand, a significant number of patients develop late haemodynamic complications, e.g. heart failure, supraventricle arrhythmias, pericarditis, pleural effusion, pulmonary vessels hypoplasia, high pressure in pulmonary vasculature (resistance), elevated central venous pressure and

Address for correspondence: dr hab. n. med. Joanna Kwiatkowska, Department of Paediatric Cardiology and Congenital Heart Diseases, Medical University of Gdansk, Poland

E-mail: joannak@gumed.edu.pl

Received: 05.04.2019; accepted: 10.06.2019; first published: 06.08.2019 protein-losing enteropathy [6]. Current treatment regimens do not reliably predict a good or bad result. A dependable non-invasive method of evaluation of Fontan circulation haemodynamics for early diagnosing unstable patients is hardly available in a routine clinical practice.

Haemodynamic changes connected with Fontan surgery intervention may increase morbidity and mortality in this group of patients, but the causes are poorly recognized $[7,8]$.

A common phenomenon observed in patients with single ventricle circulation is an elevated pulmonary vascular resistance index. It is often difficult to identify because of low cardiac output (CO) [7]. ICG as a non-invasive and repeatable diagnostic method can be useful for SV and CO assessment before surgery, and in post-operative period. There are other methods of non-invasive $\mathrm{CO}$ estimation, such as echocardiography and magnetic resonance imaging, but continuous measurement may be crucial in this group of patients [9,10]. ICG measures changes of electrical bioimpedance of the thorax during blood flow volume changes in the aorta, and determines CO and SV. During systole, morphotic elements of blood are aligned (lower impedance) and during diastole are randomly orientated (higher impedance) [10]. In recent years, it has been suggested that $\mathrm{CO}$ and $\mathrm{SV}$ measurement and the calculation of peripheral resistance might be instrumental in the diagnosis, treatment and risk stratification of paediatric cardiac patients [11]. 


\section{OBJECTIVES}

The aim of the study is non-invasive evaluation of haemodynamic parameters in patients after Fontan operation.

\section{MATERIALS AND METHOD}

Eleven patients $(24.4 \pm 4.3$ years $)$ with functionally univentricular hearts after Fontan-palliation were enrolled in the study. All patients underwent physical examination, electrocardiography (ECG), echocardiography, impedance cardiography (ICG), oxygen saturation measurements and laboratory tests. There are many studies that confirmed ICG as a reliable and cost-effective method of haemodynamic assessment in different groups of patients [12-15].

Impedance cardiography. ICG was performed twice: during a 6-minute rest period in the supine position, and afterwards in thesitting position using a Niccomo ${ }^{\mathrm{TM}}$ device (Medis, Ilmenau, Germany). Eight spot electrodes and a cuff manometer were used. Blood pressure was evaluated three times during recording.

Haemodynamic parameters were measured continuously and their values were recorded beat-to-beat. Specific calculations conducted as part of further analysis were based on the values obtained in the supine and sitting positions. The quality of all measurements was high, and no relevant errors were noted.

Statistical analysis. Statistica 12.0 (StatSoft, Inc., Tulsa, USA) for statistical analysis was used. Kolmogorov-Smirnov test was used for data distribution and normality. Continuous variables are presented as means \pm standard deviation (SD). Categorical variables are presented as absolute values and percentages. Dependent samples t-test was used for associations between haemodynamic parameters. The p-value of $<0.05$ was considered statistically significant.

\section{RESULTS}

Eleven patients after the Fontan operation were examined. Based on each patient's history, the NYHA scale was assessed. Four patients did not report impairment of exercise tolerance (NYHA I), 5 moderate impairment (NYHA II), 1 patient reported worsening exercise tolerance in recent months (NYHA II/III), and 1 is on the active heart transplant list.

Other important factors were also been analyzed which may be relevant in long-term prognosis. Two patients had protein-losing enteropathy, another 2 patients had asymptomatic thrombocytopenia, and 2 patients presented a complete atrio-ventricular block requiring epicardial pacemaker implantation. In 1 patient in the ECG and Holter ECG, ventricular arrhythmias was found.

The majority of patients did not require pharmacological treatment in addition to the prophylactic dose of acetylsalicylic acid. Three patients were provided with Sildenafil, 2 of them due to protein-losing enteropathy (additionally spironolactone, vitamin $\mathrm{K}$ antagonist and a high-protein diet). None of the patients presented central cyanosis; mean oxygen saturation was $96 \pm 2.53 \%$. The average BNP level was $38.77 \pm 39.46 \mathrm{pg} / \mathrm{ml}$ (reference $<73 \mathrm{pg} / \mathrm{ml}$ ). BNP was distinctively high in 1 patient (included on the active heart transplant list).

Echocardiography. Seven patients underwent fenestrated Fontan-paliation, but only in 1 patient in the current echocardiographic study. Echo examination revealed laminal flow in Fontan circulation in all patients, a severely impaired ejection function of single ventricle in 2 (1 patient on the active heart transplant list), and a significant aortic insufficiency in another (the patient was qualified for aortic valve replacement) and a severe common atrio-ventricular valve insufficiency in 1 patient.

Impedance cardiography. Haemodynamic parameters of the participants are presented in Table 1.

Table 1. Haemodynamic parameters in 11 patients after Fontan operation

\begin{tabular}{|c|c|c|c|}
\hline Parameter & Supine position $n=11$ & Sitting position $n=11$ & $P$ \\
\hline $\mathrm{HR}[1 / \mathrm{min}]$ & $70.1 \pm 10.3$ & $78.3 \pm 13.6$ & 0.001 \\
\hline BPsys [mmHg] & $117.2 \pm 15.0$ & $120.6 \pm 14.9$ & 0.061 \\
\hline BPdia $[\mathrm{mmHg}]$ & $73.9 \pm 9.5$ & $76.7 \pm 8.3$ & 0.026 \\
\hline MAP $[\mathrm{mmHg}]$ & $84.5 \pm 10.3$ & $88.0 \pm 9.1$ & 0.013 \\
\hline $\mathrm{CO}[\mathrm{l} / \mathrm{min}]$ & $5.3 \pm 1.8$ & $5.3 \pm 1.9$ & 0.307 \\
\hline $\mathrm{Cl}\left[\mathrm{I}^{*} \mathrm{~m}^{-2 *} \mathrm{~min}^{-1}\right]$ & $2.9 \pm 0.7$ & $3.0 \pm 0.8$ & 0.262 \\
\hline $\mathrm{SV}[\mathrm{ml}]$ & $75.4 \pm 22.0$ & $68.5 \pm 21.3$ & 0.013 \\
\hline $\mathrm{SI}\left[\mathrm{ml}^{*} \mathrm{~m}^{-2}\right]$ & $42.7 \pm 8.9$ & $39.0 \pm 9.0$ & 0.014 \\
\hline $\operatorname{TFC}\left[1^{*} \mathrm{k} \Omega^{-1}\right]$ & $38.5 \pm 4.7$ & $35.4 \pm 5.2$ & $<0.00001$ \\
\hline $\operatorname{TFCl}\left[1 * \mathrm{k} \Omega^{-1 *} \mathrm{~m}^{-2}\right]$ & $22.8 \pm 6.5$ & $21.0 \pm 6.6$ & $<0.00001$ \\
\hline SVR $\left[\mathrm{dyn}^{*} \mathrm{~s}^{*} \mathrm{~cm}^{-5}\right]$ & $1284.8 \pm 367.0$ & $1334.9 \pm 362.1$ & 0.024 \\
\hline SVRI $\left[\mathrm{dyn}{ }^{*} \mathrm{~s}^{*} \mathrm{~cm}^{-5 *} \mathrm{~m}^{-2}\right]$ & $2178.7 \pm 462.6$ & $2272.8 \pm 504.8$ & 0.018 \\
\hline LCW $\left[\mathrm{kg}^{*} \mathrm{~m}\right]$ & $5.7 \pm 2.2$ & $6.1 \pm 2.5$ & 0.077 \\
\hline LCWI $\left[\mathrm{kg}^{*} \mathrm{~m}^{*} \mathrm{~m}^{-2}\right]$ & $3.2 \pm 0.95$ & $3.4 \pm 1.0$ & 0.055 \\
\hline $\mathrm{ACl}\left[100^{*} \mathrm{ZO}^{*} \mathrm{~s}^{-2}\right]$ & $100.3 \pm 27.2$ & $100.4 \pm 23.4$ & 0.497 \\
\hline VI $\left[1000 * Z^{*} s^{-1}\right]$ & $57.2 \pm 15.8$ & $59.4 \pm 15.8$ & 0.256 \\
\hline $\mathrm{HI}\left[\Omega^{*} \mathrm{~s}^{2}\right]$ & $9.9 \pm 3.6$ & $10.8 \pm 4.0$ & 0.055 \\
\hline LVET [ms] & $291.1 \pm 35.2$ & $260.1 \pm 33.4$ & $<0.00001$ \\
\hline PEP [ms] & $124.2 \pm 22.1$ & $136.2 \pm 31.6$ & 0.009 \\
\hline STR (PEP/LVET) & $0.43 \pm 0.1$ & $0.53 \pm 0.14$ & 0.0001 \\
\hline $\mathrm{TAC}\left[\mathrm{ml}^{*} \mathrm{~mm} \mathrm{Hg}^{-1}\right]$ & $1.8 \pm 0.69$ & $1.6 \pm 0.45$ & 0.077 \\
\hline TACI $\left[\mathrm{ml}^{*} \mathrm{~mm} \mathrm{Hg}{ }^{-1 *} \mathrm{~m}^{-2}\right]$ & $1.03 \pm 0.34$ & $0.92 \pm 0.26$ & 0.095 \\
\hline Zo $[\Omega]$ & $26.2 \pm 3.0$ & $28.7 \pm 3.9$ & $<0.00001$ \\
\hline
\end{tabular}

HR - heart rate; BPsys - systolic blood pressure; BPdia - diastolic blood pressure; MAP- mean arterial blood pressure; $\mathrm{CO}$ - cardiac output; $\mathrm{Cl}$ - cardiac index; SV - stroke volume; $\mathrm{SI}$ - stroke index; TFC - thoracic fluid content; $\mathrm{TFCI}$ - thoracic fluid content index; SVR - systemic vascular resistance: SVRI - systemic vascular resistance index:LCW-leftcardiac work: LCWI-leftcardiac resistance, SVRI-systemic vascular resistance index, LCW-left cardiac Work, LCWI-left cardiac workindex; $\mathrm{ACl}$ - acceleration index; $\mathrm{VI}$-velocity index; $\mathrm{HI}$ - Heather index; LVET-left-ventricular ejection time; PEP - pre-ejection period; STR - systolic time ratio; TAC - total arterial compliance;
TACI - total arterial compliance index; Zo - baseline thoracic impedance

\section{DISCUSSION}

Patients after Fontan procedure are one of the most challenging patients in clinical practice. Heart failure is common in this group of patients. Understanding the haemodynamic mechanism and monitoring its specific 


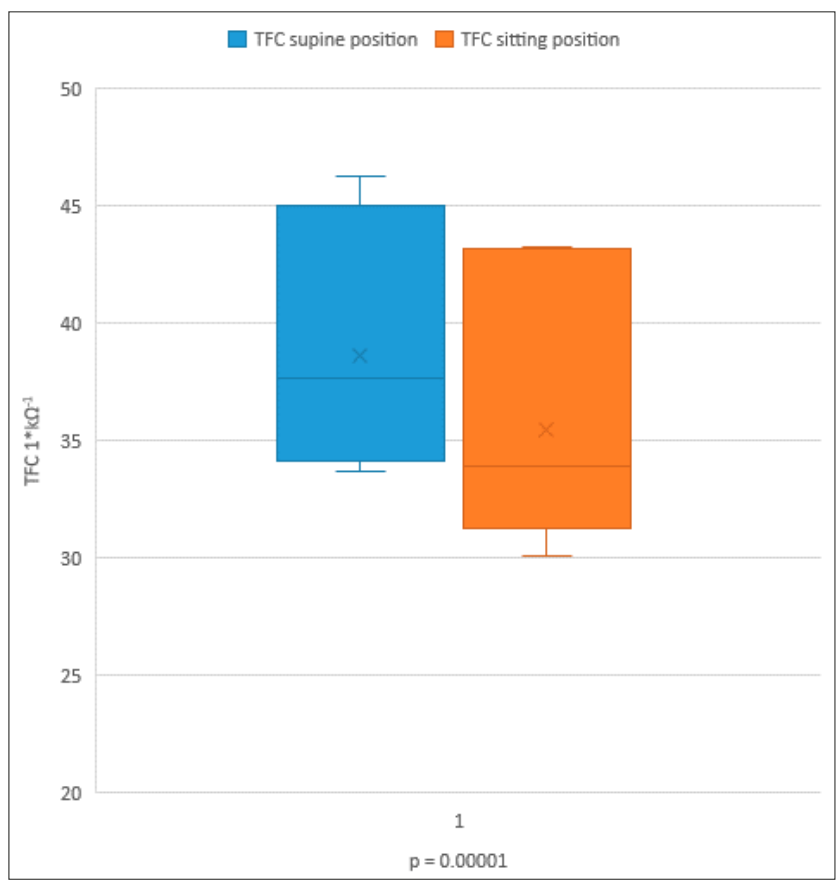

Figure 1. Thoracic fluid content (TFC) in 11 patients after Fontan operation in supine and sitting positions

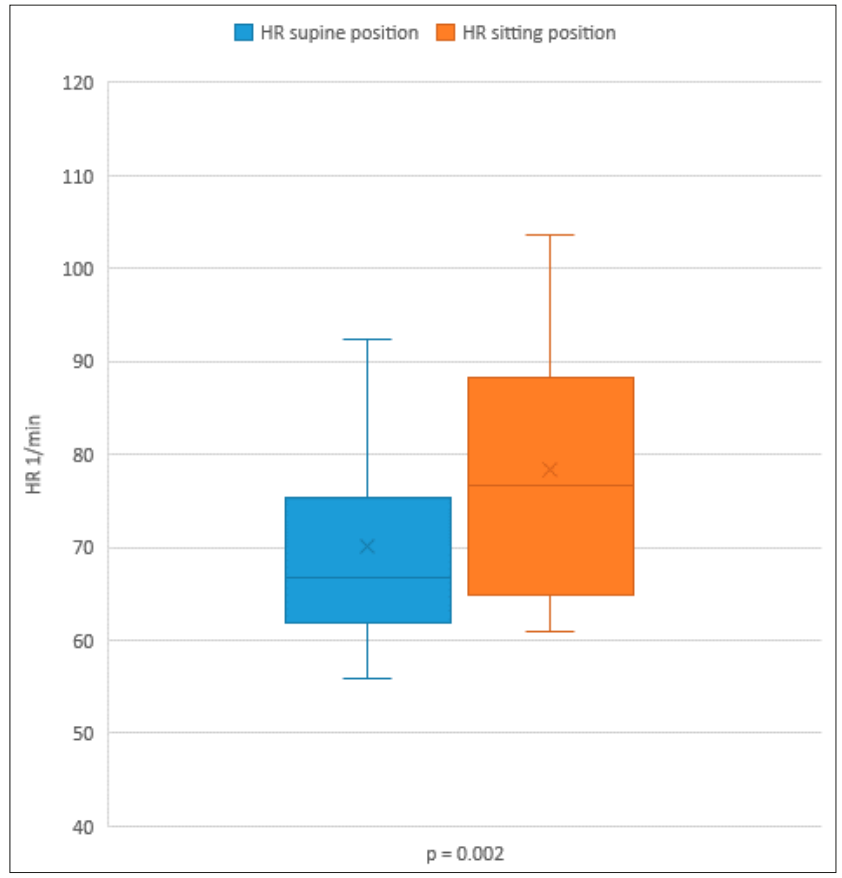

Figure 2. Heart rate (HR) in 11 patients after Fontan operation in supine and sitting positios

parameters in patients with Fontan circulation may improve survival and quality of life.

Changes in posture at rest are associated with significant changes in left ventricle (LV) filling and SV. A transition from the supine to the sitting position produces a decrease in LV end-diastolic pressure and volume and in SV [16]. In the study by Egbe et al., the highest risk of Fontan failure was the combination of high pulmonary vascular resistance index and low CI [17]. Fontan circulation is characterized by low CI, continuous lung perfusion and systemic venous hypertension [18]. Key features of the Fontan ventricle are

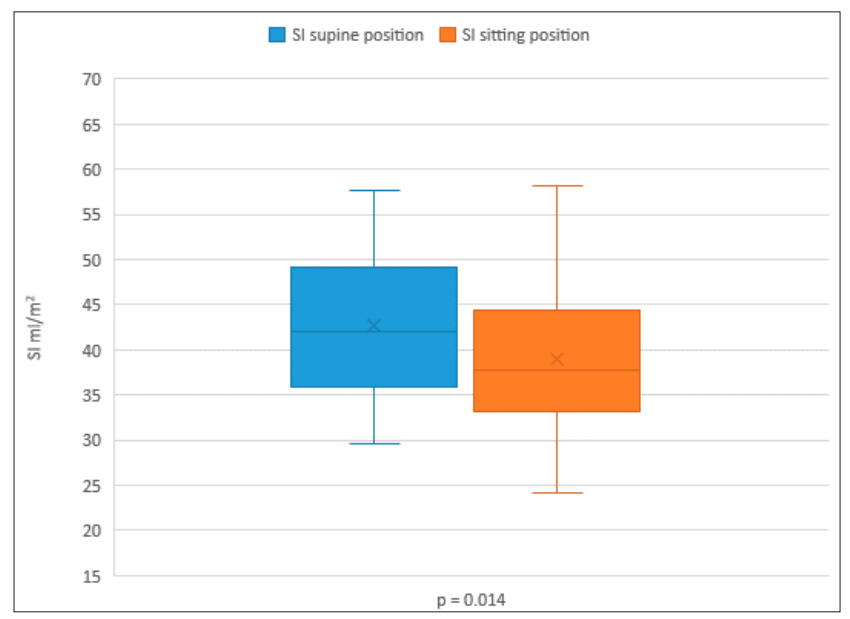

Figure 3. Stroke index $(\mathrm{SI})$ in 11 patients after Fontan operation in supine and sitting positions

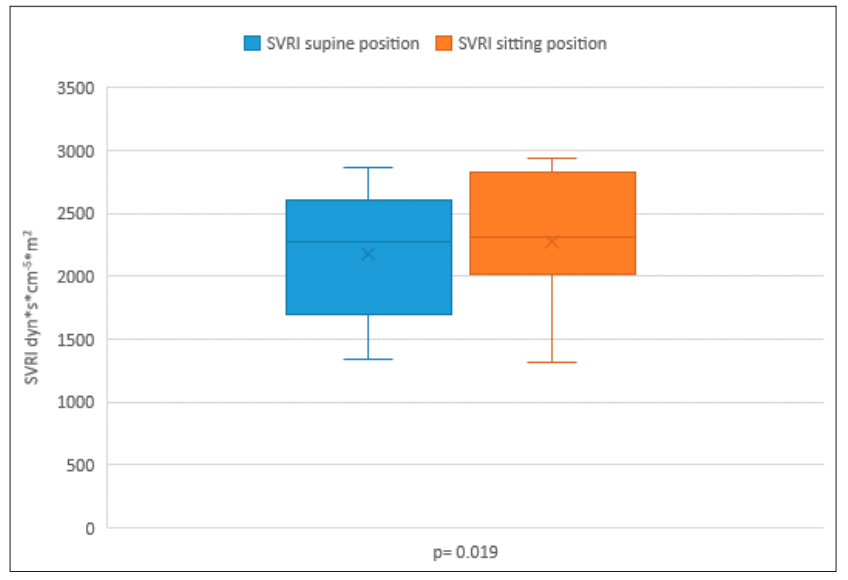

Figure 4. Systemic vascular resistance index (SVRI) in 11 patients after Fontan operation in supine and sitting positions

early volume overload and overgrowth. Because of the absence of subpulmonary ventricular stimuli, preload reserve for the systemic ventricle is reduced. In the current study, preload (TFC) decreased significantly in the sitting position. TFC and Zo reflect the changes in amount of blood in the thorax. SI decreased but the heart rate frequency increased in response to lower non-pulsative inflow to the pulmonary artery. In this way, the CI was at the same level compared with the data obtained in the supine position.

In Fontan circulation, patients preload controls $\mathrm{CO}$ and increase in HR shorten the ventricular filling time and negatively impact SI [19]. Blood pressure and SVRI increased significantly in response to decrease in the amount of blood. Changes in posture at rest are associated with significant changes in LV filling and SV. A transition from the supine to the sitting position produces a decrease in SV, probably because of afterload increase, lack of preload and/or impaired ventricular function. The higher resting SI observed in the supine position may be caused by the increased pulmonary capillary filling [19].

Data from this study indicate that during the supine and sitting positions in patients after the Fontan procedure, both the Frank-Starling mechanism and increased HR frequency play a role in CO. Previous studies showed that $\mathrm{CO}$ is the main limitation factor for Fontan surgery patients, especially by chronotropic incompetence or by inadequate increase of 
SV for others [20]. In the current study, no significant changes in $\mathrm{CO}$ and $\mathrm{CI}$ were observed, which were observed previously in exercise tests. SVR, SVRI and HR were significantly higher in the sitting position to compensate for lower SV to maintain CO. In a study by Legendre et al., reduced SV and insufficient $\mathrm{HR}$ increase reserve were responsible for reduced CI upright ramp cycle exercise [20].

There are several studies of the vasodilatory effect of oxygen on the pulmonary vasculature for evaluation of effectiveness of the ventilatory pump [21]. In healthy subjects, hyperoxaemia increases the pulmonary blood flow and decreases the HR, but CO is only slightly changed [22]. According to a study by Thompson et al., STR (PEP/LVET) measurement can be a reliable method for evaluation of ventricular systolic function, and differentiate patients with preserved and impaired ventricular systolic function [23]. In observations in the presented study, STR was elevated in the sitting position, which indicates impaired ventricular systolic function. Castellanos et al. reported that brain natriuretic peptide (BNP) and STR had a significant and independent predictive value for a long-term clinical outcome [24].

The small number of patients is a limitation in the presented study. Despite the advantages of the ICG method and its ability to monitor multiple haemodynamic parameters, there are also limitations which can significantly reduce measurement accuracy, e.g. low height $(<120 \mathrm{~cm})$ of the patient, incidence of arrhythmias and severe insufficiency of the mitral or aortic valve [25]. None of the patients fulfilled the exclusion criteria.

\section{CONCLUSION}

In patients after Fontan procedure impedance cardiography can be a useful tool for the assessment of short-term haemodynamic changes provoked by postural changes. Its clinical value in patients with congenital heart defects should be further investigated.

\section{Acknowledgments}

The study was conducted in accordance with the principles of Good Clinical Practice and the Declaration of Helsinki, with the approval of the local Bioethics Committee (Approval No. NKEBN/232/08). The study was financed by the Medical University of Gdansk (ST-72).

\section{REFERENCES}

1. Jacobs JP, Maruszewski B. Functionally Univentricular Heart and the Fontan Operation. World J Pediatr Congenit Heart Surg. 2013; 4(4): 349-55.

2. Rowland TW. The circulatory response to exercise: Role of the peripheral pump. Int J Sports Med 2001; 22(8): 558-565.

3. Cordina RL, O'Meagher S, Karmali A, Rae CL, Liess C, Kemp GJ, et al. Resistance training improves cardiac output, exercise capacity and tolerance to positive airway pressure in Fontan physiology. Int J Cardiol. 2013; 8(2): 780-8.

4. Iyengar AJ, Winlaw DS, Galati JC, Wheaton GR, Gentles TL, Grigg LE, et al. The extracardiac conduit Fontan procedure in Australia and New Zealand: Hypoplastic left heart syndrome predicts worse early and late outcomes. Eur J Cardiothorac Surg. 2014; 46(3): 465-73.

5. Ono M, Kasnar-Samprec J, Hager A, Cleuziou J, Burri M, Langenbach $\mathrm{C}$, et al. Clinical outcome following total cavopulmonary connection:
A 20-year single-centre experience. Eur J Cardiothorac Surg. 2016; 50(4): 632-641.

6. Petko M, Myung RJ, Wernovsky G, Cohen MI, Rychik J, Nicolson SC, et al. Surgical reinterventions following the Fontan procedure. Eur J Cardiothorac Surg. 2003; 24(2): 255-9.

7. Gewillig M, Goldberg DJ. Failure of the fontan circulation. Heart Fail Clin. 2014; 10(1): 105-16.

8. Pundi KN, Johnson JN, Dearani JA, Pundi KN, Li Z, Hinck CA, et al. 40-Year Follow-Up after the Fontan Operation: Long-Term Outcomes of 1,052 Patients. J Am Coll Cardiol. 2015; 66(15): 1700-10.

9. Beck R, Milella L, Labellarte C. Continuous non-invasive measurement of stroke volume and cardiac index in infants and children: comparison of Impedance Cardiography $\mathrm{NICaS}^{\star}$ vs CardioQ ${ }^{\circ}$ method. Clin Ter. 2018; 169(3): e110-e113.

10. Yoshitake S, Miyamoto T, Tanaka Y, Naito Y. Non-invasive measurement of cardiac output using AESCULON ${ }^{\circledR}$ mini after Fontan operation. Pediatr Int. 2017; 59(2): 141-144.

11. Beck R, Milella L, Labellarte C. Continuous noninvasive measurement of stroke volume and cardiac index in infants and children: comparison of Impedance Cardiography NICaS ${ }^{\circledR}$ vs CardioQ ${ }^{\circledR}$ method. Clin Ter. 2018; 169(3): e110-e113.

12. Charloux A, Lonsdorfer-Wolf E, Richard R, Lampert E, OswaldMammosser M, Mettauer B, et al. A new impedance cardiograph device for the non-invasive evaluation of cardiac output at rest and during exercise: comparison with the "direct" Fick method. Eur J Appl Physiol. 2000; 82(4): 313-20.

13. Lorne E, Mahjoub Y, Diouf M, Sleghem J, Buchalet C, Guinot P-G, et al. Accuracy of impedance cardiography for evaluating trends in cardiac output: a comparison with oesophageal Doppler. Br J Anaesth. 2014; 113(4): 596-602.

14. Appel PL, Kram HB, Mackabee J, Fleming AW, Shoemaker WC. Comparison of measurements of cardiac output by bioimpedance and thermodilution in severely ill surgical patients. Crit Care Med. 1986; 14(11): 933-5.

15. Krzesiński P, Gielerak G, Kowal J. Impedance cardiography - a modern tool for monitoring therapy of cardiovascular diseases. Kardiol Pol. 2009; 67(1): 65-71.

16. Poliner LR, Dehmer GJ, Lewis SE, Parkey RW, Blomqvist CG, Willerson JT. Left ventricular performance in normal subjects: a comparison of the responses to exercise in the upright and supine positions. Circulation. 1980; 62(3): 528-34.

17. Egbe AC, Connolly HM, Miranda WR, Ammash NM, Hagler DJ, Veldtman GR, et al. Hemodynamics of Fontan Failure: The Role of Pulmonary Vascular Disease. Circ Heart Fail. 2017; 10(12). pii: e004515.

18. Gewillig M, Goldberg DJ. Failure of the Fontan Circulation. Heart Fail Clin. 2014; 10(1): 105-16.

19. Hebert A, Jensen AS, Mikkelsen UR, Idorn L, Sørensen KE, Thilen U, et al. Hemodynamic causes of exercise intolerance in Fontan patients. Int J Cardiol. 2014; 175(3): 478-83.

20. Legendre A, Guillot A, Ladouceur M, Bonnet D. Usefulness of stroke volume monitoring during upright ramp incremental cycle exercise in young patients with Fontan circulation. Int J Cardiol. 2017; 227: 625630.

21. Ley S, Puderbach M, Risse F, Ley-Zaporozhan J, Eichinger M, Takenaka $\mathrm{D}$, et al. Impact of oxygen inhalation on the pulmonary circulation: Assessment by magnetic resonance (MR)-perfusion and MR-flow measurements. Invest Radiol. 2007; 42(5): 283-90.

22. Körperich H, Müller K, Barth P, Gieseke J, Haas N, Schulze-Neick I, et al. Differentiation of Impaired from Preserved Hemodynamics in Patients with Fontan Circulation Using Real-time Phase-velocity Cardiovascular Magnetic Resonance. J Thorac Imaging. 2017; 32(3): 159-168.

23. Thompson B, Drazner MH, Dries DL, Yancy CW. Systolic Time Ratio by Impedance Cardiography to Distinguish Preserved vs Impaired Left Ventricular Systolic Function in Heart Failure. Congest Heart Fail. 2008; 14(5): 261-5.

24. Castellanos LR, Bhalla V, Isakson S, Daniels LB, Bhalla MA, Lin JP, et al. B-Type Natriuretic Peptide and Impedance Cardiography at the Time of Routine Echocardiography Predict Subsequent Heart Failure Events. J Card Fail. 2009; 15(1): 41-7.

25. Siedlecka J, Siedlecki P, Bortkiewicz A. Impedance cardiography - Old method, new opportunities. Part I. Clinical applications. Int J Occup Med Environ Health. 2015; 28(1): 27-33. 